| Volume-1 | Issue-1 | Jul-Aug 2019 |

Original Research Article

\title{
A Theological Perspective on the Future of Black Philosophy
}

\author{
Kiatezua Lubanzadio Luyaluka, Ph. D. (hon.) * \\ Institut des Sciences Animiques, Kinshasa, Democratic Republic of Congo, Africa

\section{*Corresponding Author} \\ Kiatezua Lubanzadio Luyaluka
}

\section{Article History}

Received: 28.07.2019

Accepted: 12.08 .2019

Published: 30.08 .2019

\begin{abstract}
This paper contends that the future of Black philosophy should be grasped from the theological perspective which entails catching the conditions that prevailed in the Egyptian religious epistemic paradigm before the rise of speculative philosophy among the Grecian elite. The reason given for this conviction is that according to the prospective of Cheikh Anta Diop and the concordant predictions of ancient Egyptian and Sumerian mages as well Kôngo prophets, we are at the wake of an epistemic shift which will bring back the rise of the preponderance of the African spiritually based mode of thinking over the Western materialistic trend. It appears from this perspective that the reemergence of African traditional religion as an exact science, i.e., a coherent set of deductive knowledge, will force Black philosophy back to a low-key position where it will be recognized for what it epistemologically really is: a Western paradigm dealing with African issues.
\end{abstract}

Keywords: theology; cosmological argument; Back philosophy; African traditional religion; Grecian philosophy; epistemology.

\section{INTRODUCTION}

From its inception by the book of Placid Tempels [1] titled la Philosophie Bantoue, the concept of African philosophy has been met with dubitative Western voices raising concerns about its valid existence [2]. Although since then a great deal of works has been done within the topic of African philosophy, the existence of the paradigm as an African one, remains an open question. This is seen for instance in the fact that "an extensive portion of the literature on African philosophy is devoted to the polemic surrounding the issue of the existence and essence of African philosophy" [3].

The purpose of this paper is the study of the future of Black philosophy within the context of the open question of the existence of an African philosophy. For this endeavor, we aim to contend that in order to speak of the future of Black philosophy a great need is the use of a methodology that can bring in a new perspective on the question of the very existence of a Black philosophy. This can be done through a perspective based on theological perception of the relationship that might or not exist between religion and speculative philosophy within the context of the true African epistemic paradigm.

It is well known that "the question 'what is philosophy' is one of the most difficult question in philosophy" [3]. Therefore, we will handle the problem of the future of Black philosophy within the limits of speculative philosophy as an academic discipline, i.e., a branch of scientific knowledge.

\section{METHODOLOGICAL APPROACH}

We intend to contend that, the question of the future of Black philosophy must be handled in a theological perspective that catches the epistemic conditions that prevailed in the Egyptian religion before the birth of Grecian speculative philosophy in $600 \mathrm{BC}$ [3]. The importance of this endeavor is seen in the need to answer the following questions: what was the relationship between the religion of ancient Egypt and Grecian speculative philosophy? In what extent the epistemic paradigm of ancient Egypt influenced Grecian speculative philosophy? Is there a genesial connection between both episteme?

The necessity of raising these questions is seen in the fact that, firstly, in ancient Egypt, "all sciences and all inventions are (...) linked to religion and to moral" [4]; secondly, Western philosophy grew out of religion and mythology" [3]. This means that a

Copyright @ 2019: This is an open-access article distributed under the terms of the Creative Commons Attribution license which permits unrestricted use, distribution, and reproduction in any medium for non commercial use (NonCommercial, or CC-BY-NC) provided the original author and source are credited. 
genesial connection exists between speculative philosophy and religion. Thus, understanding the relationship which existed between the religion of ancient Egypt and Grecian speculative philosophy might be instrumental in grasping the future relationship that will prevail between speculative philosophy and African traditional religion (ATR), an instance which could be a repetition of an old occurrence.

\section{On the ancient relationship between religion and speculative philosophy}

We know that some authors have surmised that Grecian speculative philosophy was taken full-orbed from the bank of the Nile $[5,6]$, which implies that the relationship that marked the religion and ancient Egypt and Grecian speculative philosophy was one of inclusion of the later in the former. But, from an historical approach, it is not an easy thing to define this relationship. Firstly, because the Grecian students of Egyptian mysteries who could give us this knowledge are mute on the subject; secondly the presentation of the religion of ancient Egypt by Eurocentric-minded scholars was biased at such a point that its true epistemic import was marred, as will be seen bellow.

However, the difficulty of seizing historically the relationship between the religion of ancient Egypt and Grecian speculative philosophy can be circumvented thanks to the kemetic cosmological argument (KCA). The KCA is an argument about the existence of God which, contrary to Western cosmological arguments, extends to the essential doctrines of the religion that characterized ancient Egypt and Sumer. Now the epistemological identity of African traditional culture with these two ancient civilizations and the southward migration of south-Saharan ethnics from the confines of the Middle East imply that the KCA defines the original nature of ATR; a nature which is continued in Kôngo religion, Bukôngo [7].

Thus, the KCA can help us understand the true nature of the religion of ancient Egypt and cast light on its relationship with Grecian speculative philosophy. This understanding will enables us to prospectively arrive to the knowledge of the future conditions of Black philosophy because the KCA defines also the true nature that ATR can regain in this future.

\section{A Brief introduction of the KCA}

Cosmological arguments have been used since Plato's book the Law to demonstrate the existence of a first cause of this temporal universe by reasoning from "the presence of the cosmos back to a creator of the cosmos" [8]. Though, as used in Western theology, this argument is successful in its endeavor, Rowe [9] warns us that "there remains the difficult task of establishing that the first cause or self-existent being is God" (373).

Contrary to the limitations met by Western theological tradition in its cosmological arguments, the KCA extends into a systematic natural theology; it offers therefore a scientific model of religion. This argument can be introduced summarily in this manner:

- As an aggregate of individual entities and particular circumstances, this visible universe has an individuality.

- According to the law of causality, there is a necessary entity which causes this temporal universe and by hypothesis includes it.

- The cause of an individual universe has individuality.

- $\quad$ Thus, there are other necessary causes at least potentially causative.

- A greatest being exists who is the sum total of the above induced relative necessary beings and causes their individualities.

- Being the ultimate cause, this last being is God. Thus, God is absolutely infinite, absolutely non-contingent, indivisible and immutable. Any lesser nature would invite the existence of a cause higher than the greatest being,this is impossible.

- Due to the indivisibility of God, every relative necessary being, as his manifestation, expresses his completeness. This completeness we call the Word.

- The Most-high, the Word and the relative necessary being are inseparable in their existence, substance and activity due to the divine indivisibility. The Most-high always acts through the relative necessary being thanks to the Word. The relative necessary being always acts for the Most-high thanks to the Word. This we call "solartrinity".

From this introduction, we have thus far extended this systematic natural theology to the following branches: theology proper, doctrine of the Word, anthropology, theodicy, pneumatology, harmatiology, ethics, soteriology, and cosmology [10-12].

About cosmology, a question arises here: what is the nature of this visible universe? The transcendence and absolute noncontingence of the Most-high implies that creation cannot occur in the divine consciousness. Moreover, as a necessary being the creator cannot leave the celestial realm. Therefore, creation occurs in an intermediary temporal plan. Since God includes all realities, creation is only a limited perception of this celestial reality. However, this limitation can only be illusory, because the good that appears in the temporal order has its substance in God who includes all.

\section{On the scientific validity of the KCA}

The KCA is a deduction, a mode of reasoning for the validity of which "it is not possible for the premises all to be true while the conclusion is false" [13]. Now the premises of the KCA are the existence of individualities in this visible universe and the law of 
causality. The existence of individualities is obvious; one can deny it only as he has an opinion contrary to ours, which is an affirmation of individuality.

An objection can be made as to the law of causality as it doesn't govern the field of quantum physics. However, the KCA result in a cosmology which offers a valid alternative to the explanation of the quantum wave/particle dilemma by demonstrating that subatomic elements are true particles on undulating trajectories. Moreover, this cosmology of the KCA results in a deterministic explanation of the dynamics of the universe (gravitation, rotation and translation) at the astronomic and subatomic levels, a "theory of everything". This shows that Einstein was right, "beneath the chaos of the quantum might lie hidden a scaled-down version of the wellbehaved, familiar world of deterministic dynamics" [14].

Since, this cosmology drawn from the KCA is the simplest and mathematically verified explanation of the dynamics of the universe; it adds a second argument about the scientific validity of the KCA. Thus, this systematic natural theology is an exact science, i.e., a set of coherent deductive truths.

\section{The KCA and the relationship between Egyptian religion and Grecian philosophy}

As a systematic natural theology, the KCA is a scientific model of religion that exposes among others the following fundamental truths:

- The transcendence of the Most-high.

- The existence of two principles (a creator and the Word) participating directly in the creation of a temporal universe

- The relative necessary beings manifest the full glory of God because he is indivisible.

- The apparent nature of the phenomena of this temporal universe as illusory limited manifestation of celestial realities in the temporal consciousness of the creator. etc.

That the KCA defines the religion that characterized the civilization of ancient Egypt is seen in the parallel correlation that can be established between both episteme. Though the above doctrines of KCA are not exhaustive, their parallel correlation with the religion and ancient Egypt provides the proof of the scientificity of the later. This correlation can be seen among others in the following:

- The existence of the Most-high God in ancient Egypt is affirmed by the Egyptian book titled the Pyramid text of Unas which alludes to him explicitly as the "Sole Lord" [15], and by the Egyptian book of the dead which alludes to him by speaking of the creator Ra as Child of Nut (the heaven), thus implying the existence of a higher order genitor of Ra.

- The transcendence of the Most-high God is seen in the fact that he was neither named nor "represented by any material, even symbolical, form" [16]; thus prayers were never addressed to him, but to Ra, the creator, through lower divinities.

- The existence of two creative principles in Memphis theology is affirmed by the Shabaka stone, an inscription about the theology of Memphis rescued by the Nubian pharaoh Shabaka of the XVIIlth dynasty [ca. 1539-1292 BCE]. Alluding to this doctrine James (2009) mentions Atom (the creator) and Ptah (the Word).

- The apparent nature of the phenomena taught by Plato finds an echo among the Yoruba [17] of Nigeria and among the Luba/Katanga of Democratic Republic of Congo [1]. This dispersion is a clear proof of its Egyptian origin, in as much as Plato was a student of Egyptian mysteries [18].

- That the necessary beings irradiate the full glory of the Most-high is seen in Egypt in the fact that each of them is called Ra (the Sun).

- That creation happens in the consciousness of the creator is seen in the depiction of the Nut, Shu, Geb scene where the necessary relative beings are depicted as suns in consciousness of the Most-high like the reeds in the body of Geb represent creation in the consciousness of the creator.

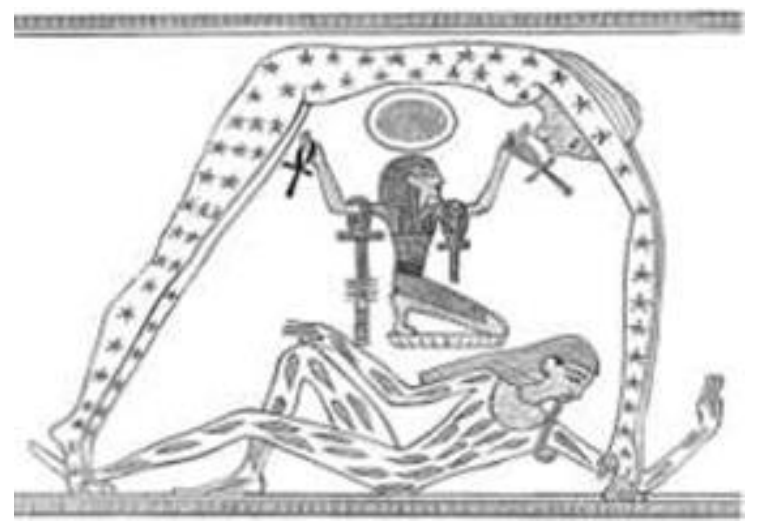

Fig-1: the Nut, Shu, Geb scene

Retrieved from http://hubpages.com/education/Osiris-and-Isis-An-Egyptian-Love-Story. 
These correlations are a clear proof that the KCA is the systematic natural theology of the religion of ancient Egypt. Therefore, this religion was an exact science, i.e., a set of coherent deductive truths. This being the case, from the Egyptian divine science to Grecian speculative philosophy, the relationship of both paradigms can be defined only as a devolution of the former into the later; and this disproves the affirmation that Grecian speculative philosophy originated from ancient Egypt as a full-orbed paradigm.

This correlation of the KCA and the religion of ancient Egypt can be extended to the culture of Sumer and to Bukôngo, which is the present continuation of this religion as can be seen in the following table:

\begin{tabular}{|c|c|c|c|}
\hline KCA & Egypt (Memphis) & Sumer & Kôngo \\
\hline Most-high & Sole Lord & An & Nzâmbi Ampûngu \\
\hline Creator & Atom & Enkai & Mbumba Lowa \\
\hline Word & Ptah, God of order & Enlil, the governor & Mpina Nza, God governor \\
\hline Lower Gods & The "dead" God & The "dead" God & Kôngo \\
\hline
\end{tabular}

The divinities of Bukôngo on this table are from a prayer of the Simong Kimbangu given during a sermon at Mbanza-Nsanda (DRC) [19]. The existence of the "dead God" in Egypt is affirmed by Maspero (n.d.) and in Sumer by Kramer [20].

\section{The KCA and the epistemology of the ancient Egyptian paradigm}

One of the accents that mark the epistemology of ancient Egypt is its insistence on the freedom of the soul from the body. Freedom depicted in the iconography as the bird and a butterfly hovering over a human being or his corpse (Maspero, n.d.). Now in this revelatory epistemology scientific knowledge has been shown as including religion and being based on the following truths:

- Reality is spiritual,

- Any truth is revelation,

- Any truth is included in the knowledge of God,

- Matter is only a limited perspective on spiritual reality.

Contrary to the a priori presuppositions of Western science (the main on which is that reality material), these bases are proven to be a posteriori because, the KCA has deductively demonstrated that all reality is God; that, God being the ultimate cause, any truth is a revelation from him thanks to the Word; and that what we call material phenomena are only appearances of the celestial reality, thus reality is spiritual. Therefore, science and religion in ancient Egypt were built on scientifically demonstrable bases.

According to Grayling cited by Anthony [21], "the aim of philosophical inquiry is to gain insight into questions about knowledge, truth, reason, reality, meaning, mind, and value" (88). We can thus conclude that Grecian philosophy grew out of the inability of Hellenian religion and mythology to answer these questions. However, the very epistemological nature of the religion of ancient Egypt implies that these questions were satisfactorily answered by the priests through divine science.

\section{The future of the African episteme}

In a paper delivered during a colloquium on philosophy and religion, Cheikh Anta Diop [22], after a prospective analysis of the evolution of scientific knowledge, stressed the need of a return to a past of the cohabitation of science and religion. Diop was foreseeing the contribution of Africans as instrumental to this inevitable move. Now, the return of the cohabitation of science and religion is none other than the paradigm of ancient Egypt where religion was a science.

This prospective foresight of Diop coincides with the prediction of the mages of Sumer, as reported by the Persians, who affirmed that the materialistic dichotomous paradigm which separate science and religion and the spiritually based paradigm take turn every 3000 years. Speaking of the spiritual phase of the cycle Egyptians spoke of "the return of the Osiris from the Amenti" [16].

The Kôngo prophets allude to the same event as can be seen in the affirmation of the great prophet Simon Kimbangu: "the Black man will become White, and the White man will become Black" [19]. He meant by this an epistemological shift from the materialistic to the spiritually based mode of thinking. According to these prophecies, we are right now at the wake of this shift.

\section{CONCLUSION: THE FUTURE OF BLACK PHILOSOPHY}

We envisage the future of Black philosophy only in connection with the return of the cohabitation of science and religion foreseen by Diop and prophesied by the ancient civilizations. Therefore, the discovery, thanks to KCA, of the scientific nature of the religion that characterized the ancient civilizations of Egypt and Sumer, coupled to the sameness of the epistemological settings of African ethnics and their southward migration from the confine of the Middle East, lead to the conclusion that this scientific religion is the original nature of ATR, a nature continued in Bukôngo. 
Therefore, the future of scientific episteme foreseen by Diop and the African mages implies the return of the epistemological conditions that prevailed in the lore of ancient Egypt at the birth of speculative philosophy in VIth century BCE.

Now, as we have seen above, these epistemological conditions lead to a paradigm in which religion meets the philosophical questions of humanity in a deductive scientific way. Therefore, since speculative philosophy grew out of the inability of Grecian religion and mythology to give satisfactory answers to these questions, the return of the African scientific paradigm to its revelatory epistemological paradigm will take away from speculative philosophy the reason of its existence as an African episteme.

Therefore, the reenactment of the epistemological events of the past means that the future of Black philosophy should be expected to be a return of this scientific episteme to what it really is right now: a mere western discipline dealing with African issues.

\section{Author Biography}

Kiatezua Lubanzadio Luyaluka has a PhD (honors) degree from Trinity Graduate School of Apologetics and Theology, Kerala, India. He is currently the Director of the Institut des Sciences Animiques, an Afrocentric research and initiatory center focusing on African spirituality and epistemology. His publications in apologetics center on a defense of African spirituality and epistemology.

\section{REFERENCES}

1. Tempels, P., \& Rubbens, A. (1945). La philosophie bantoue.

2. Batolo Magoza ma Dobo. (1979). La Philosophie en Afrique, in J. Dubois \& L. van den Wijngaert (eds) Initiation Philosophique, 223-237.

3. Jinadu, A. M. (2014). Rethinking the comparison between African and Western Philosophies. Inter. J. Polit. Sci. Develop, 2(8), 180-187.

4. Lecoutre, B., Mabika, B., \& Derzko, G. (2002). Assessment and monitoring in clinical trials when survival curves have distinct shapes: a Bayesian approach with Weibull modelling. Statistics in Medicine, 21(5), 663-674.

5. Wallentin, L., Becker, R. C., Budaj, A., Cannon, C. P., Emanuelsson, H., Held, C., ... \& Mahaffey, K. W. (2009). Ticagrelor versus clopidogrel in patients with acute coronary syndromes. New England Journal of Medicine, 361(11), 1045-1057.

6. Théophile, O. (1990). La philosophie africaine de la période pharaonique. Paris, L'Harmattan.

7. Luyaluka, K. L. (2016). An essay on naturalized epistemology of African indigenous knowledge. Journal of Black Studies, 47(6), 497-523.

8. Thompson, B., \& Jackson, W. S. (1996). The Case for the existence of God. Montgomery, AL: Apologetics Press.

9. Rowe, W.L. (2010). Cosmological arguments. In C. Taliaferro, P. Draper, \& P. L. Quinn (Eds.), A companion to philosophy of religion, 368-374.

10. Luyaluka, K. L. (2014). Religion and science conversion possibility: Towards the formulation of a systematic theodicy of African traditional religion and its reinterpretation of empirical cosmology. Journal of Pan African Studies, 7(7), 108-139.

11. Luyaluka, K. L. (2017). Solar religion: A scientific source of African normative ethics. Africology: The Journal of Pan African Studies, 10(5), 66-83.

12. Luyaluka, K. L. (2018). The theory of general devolution: A call for an African solar renaissance. Journal of Black Studies, 49(7), 627-646.

13. Bonnet, X., Pearson, D., Ladyman, M., Lourdais, O., \& Bradshaw, D. (2002). 'Heaven'for serpents? A mark-recapture study of tiger snakes (Notechis scutatus) on Carnac Island, Western Australia. Austral Ecology, 27(4), 442-450.

14. Heisenberg, W. (1989). Remarks on Dirac's theory of the positron. In Original Scientific Papers / Original Scientific Papers (pp. 132-154). Springer, Berlin, Heidelberg.

15. Van den Dungen, Wim. n.d. The Pyramid Text of Unas, http://www.maat.sofiatopia.org/wenis_text.htm.

16. Rawlinson, G. (1886). History of ancient Egypt (Vol. 2). John B. Alden..

17. Omotosho, I. F. (2014). Critique of the Question of $\$$ frican Philosophy. 265-RXUQDO R/+ XPDQLWLHV \$ QG 6RFLDO 6FLHQFHV, 265, 66, 61-66.

18. Diop, C. A. (1972). Antériorité des civilisations nègres [Anteriority of Black civilizations]. Abidjan, Côte d'Ivoire: Présence africaine.

19. Bandzouzi, A. (2002). le Kimbanguisme. Paris: Eki.

20. Kramer, S. N. (1981). History begins at Sumer: Thirty-nine firsts in recorded history. University of Pennsylvania press.

21. Anthony, K. I. (2014). The meaning and nature of African philosophy in a globalising world. International Journal of Humanities Social Sciences and Education (IJHSSE), 1(7), 86-94.

22. Diop, C. A. (1984). Les Crises majeures de la philosophie contemporaine. Revue sénégalaise de philosophie, 5-6. 